\title{
The Analysis of Convection Experiment
}

\author{
Zilong Zhang \\ School of North China Electric Power University, Baoding 071000, China \\ 1406915672@qq.com
}

Keywords: convection; numerical method; the lumped parameter method.

Abstract. The paper mainly discusses the temperature distribution in eggs from the heating process. For eggs' heating process, the paper would explore the temperature change rules from the analysis, the lumped parameter method, numerical method of three aspects. Based on each methods, diagrams would be drawn, the features of temperature is going to analyze and the errors would be calculated.

\section{Problem Analysis}

Heating an egg and putting it into the boiling water at $100^{\circ} \mathrm{C}$, then the analysis objective is the variation of temperature in the center of the egg. It is assume that egg density is $1000 \mathrm{~kg} / \mathrm{m}^{3}$, the specific heat of egg is $3310 \mathrm{~J} /(\mathrm{kg} * \mathrm{k})$ and during the heating process, the surface heat transfer coefficients for $\mathrm{h}$ equals $1200 \mathrm{~W} /\left(\mathrm{m}^{2} * \mathrm{k}\right)$. The paper uses lumped parameter method, numerical analysis method and conducts two-dimensional mathematical simulation.

\section{Heating Process}

The arranged recording data of experiment is shown in Appendix 1. The real heating curve can be obtained by data fitting using Matlab.

Table 1The arranged recording data of experiment

\begin{tabular}{|c|c|c|c|c|c|c|c|c|c|c|c|}
\hline $\begin{array}{c}\text { Time } \\
/ \mathrm{s}\end{array}$ & $\begin{array}{c}\text { Temp. } \\
/{ }^{\circ} \mathrm{C}\end{array}$ & $\begin{array}{c}\text { Time } \\
/ \mathrm{s}\end{array}$ & Temp. $/{ }^{\circ} \mathrm{C}$ & $\begin{array}{c}\text { Time } \\
/ \mathrm{s}\end{array}$ & $\begin{array}{c}\text { Temp. } \\
/{ }^{\circ} \mathrm{C}\end{array}$ & $\begin{array}{c}\text { Time } \\
/ \mathrm{s}\end{array}$ & \begin{tabular}{c} 
Temp. $/{ }^{\circ} \mathrm{C}$ \\
\hline$/ \mathrm{s}$
\end{tabular} & $\begin{array}{c}\text { Time } \\
/{ }^{\circ} \mathrm{C} .\end{array}$ & $\begin{array}{c}\text { Time } \\
/ \mathrm{s}\end{array}$ & $\begin{array}{c}\text { Temp. } \\
/{ }^{\circ} \mathrm{C}\end{array}$ \\
\hline 2 & 21 & 35 & 32 & 78 & 43 & 137 & 54 & 198 & 65 & 324 & 76 \\
\hline 6 & 22 & 45 & 33 & 81 & 44 & 142 & 55 & 217 & 66 & 335 & 77 \\
\hline 10 & 24 & 51 & 35 & 92 & 46 & 153 & 57 & 229 & 68 & 361 & 79 \\
\hline 14 & 25 & 53 & 36 & 97 & 47 & 157 & 58 & 234 & 69 & 375 & 80 \\
\hline 16 & 26 & 55 & 37 & 104 & 48 & 160 & 59 & 238 & 70 & 388 & 81 \\
\hline 19 & 27 & 59 & 38 & 108 & 49 & 163 & 60 & 255 & 71 & 401 & 82 \\
\hline 21 & 28 & 66 & 39 & 112 & 50 & 170 & 61 & 274 & 72 & & \\
\hline 23 & 29 & 72 & 40 & 123 & 51 & 173 & 62 & 290 & 73 & & \\
\hline 27 & 30 & 76 & 41 & 129 & 52 & 189 & 63 & 303 & 74 & & \\
\hline 30 & 31 & 77 & 42 & 133 & 53 & 192 & 64 & 315 & 75 & & \\
\hline
\end{tabular}

Analysis calculation is performed first, then the lumped parameter method is used. The process of heating eggs belongs to unsteady heat conduction. The eggs can be seen as high thermal conductive objects and it also can be considered as a whole isothermal egg. The egg temperature of lumped-parameter equation can be written. Calculating internal egg temperature changes over time, the temperature distribution mapping can finally obtained.

The use of numerical method is to discrete the region first and divide egg into 11 regions and then the forward and implicit difference equations can be displayed respectively and using iterative method to solve forward difference equation, it can obtain temperature change results and finally 
the comparison of temperature distribution is made.

\section{Model Assumption}

It is assumed that egg is a sphere with $5 \mathrm{~cm}$ diameter. In the heating process, the convective heat transfer coefficient remains unchanged. In the lumped parameter method, egg is assumed to be a sphere with uniform temperature.

\section{Symbol Illustration}

$\lambda$ : Interior thermal conductivity of egg; $\varepsilon$ : egg surface heat conduction coefficient; $r:$ the sphere radius of egg; $\rho$ : egg density; $c$ : egg specific heat; $h$ : egg surface heat transfer coefficient; $\tau$ : time; $u$ : egg temperature; $M$ : node location

\section{Model Building and Solution}

\subsection{Heating process analysis}

Making fitting of data, the real temperature variation over time can be obtained.

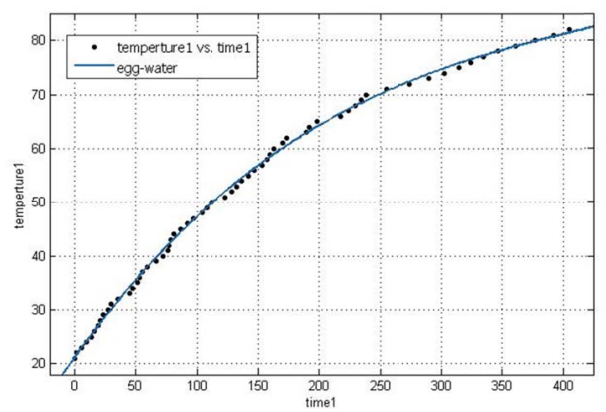

Fig. 1 real temperature variation

Using the analysis method, it is calculated that when the temperature in the center of egg comes to $82^{\circ} \mathrm{C}$, it needs $635 \mathrm{~s}$.

Hurstwood: $B i=\frac{h R}{\lambda}, B i=\frac{1200 * 0.025}{0.7}=42.86$

Coefficient of volume expansion: $a=\frac{\lambda}{\rho c} ; a=\frac{0.7}{3310 * 1000}=2.415 * 10^{-7}$

It is assumed that when the center temperature of eggs reaches 82 degrees, it comes into the formal stage (Fig. 2).

Transcendental equations characteristic root:

$$
\begin{aligned}
& 1-u_{n} \cot u_{n}=B i \quad n=1.2 \ldots \ldots \\
& u_{1}=3.032 ; \quad \frac{\theta_{m}}{\theta_{0}}=\frac{82-100}{20-100}=0.025 \quad ; \quad 2 \frac{\sin u_{1}-u_{1} \cos u_{1}}{u_{1}-\cos u_{1} \sin u_{1}}=-2.0
\end{aligned}
$$




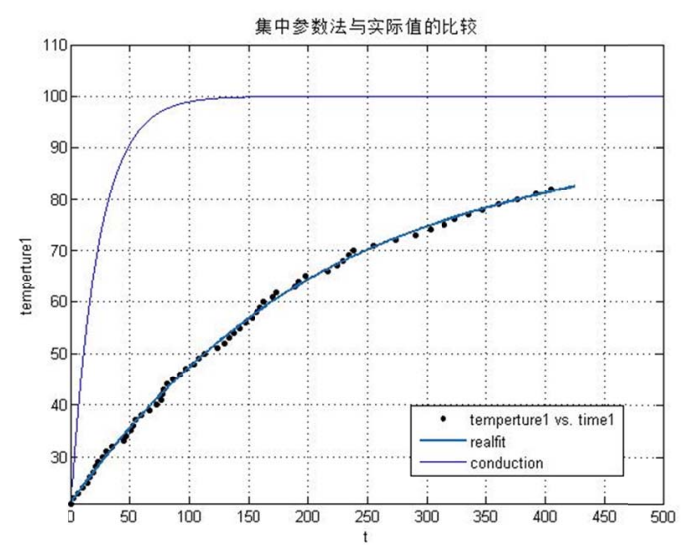

Fig. 2 formal stage

In the center of egg:

$\eta=\frac{r}{l}=0 ; \lim _{x \rightarrow 0} \frac{\sin x}{x}=1 ; \frac{-2.0}{3.092 * \eta} \sin (3.092 * \eta) \exp \left(-3.092^{2} \bullet F o\right)=-2.0 * \exp (-3.0322 \bullet F o)=0.222$ the root is:

$$
F_{0}=0.24 ; F_{0}=\frac{a t}{R^{2}}=\frac{1.51 * 10^{-7}}{0.022} \tau \Rightarrow \tau=635 ;
$$

\section{2 heating process lumped parameter method}

In the heating process, it is seen that internal thermal conductivity of the eggs is much larger than the convective heat transfer coefficient of the egg surface, so it can be concluded that the temperatures inside the egg are basically consistent.

Boundary condition: $\tau=0, \theta=t_{0}-t_{\infty}=\theta_{0}$;

Average temperature changes over time:

$$
t=\exp \left(-\frac{h A \tau}{\rho c V}\right)\left(t_{0}-t_{\infty}\right)+t_{\infty}
$$

Through the calculated result, it can obtain that (Fig. 3):

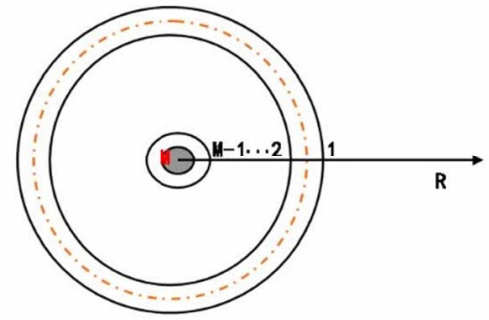

Fig. 3 the temperatures inside the egg

It can be concluded that the image obtained by lumped parameter method has great error comparing with the actual value, so it can't be selected as the mathematical model of heating the eggs.

\subsection{Numerical method of heating process}

First, the regional discrete inside the egg is made and the number of discrete regions are 11 which can be seen in Fig. 4.

The mathematical model is : $\frac{\partial t}{\partial \tau}=\frac{a}{r^{2}}\left(\frac{\partial}{\partial r}\left(r^{2} \frac{\partial t}{\partial r}\right)\right)$

Boundary condition:

$$
\tau=0, t=t_{0} ; r=0, \frac{\partial t}{\partial r}=0 ; r=r_{3},-\lambda \frac{\partial t}{\partial r}=h\left(t-t_{\infty}\right) ; \nabla r=0.15 / M
$$

Forward difference format equations (one node): 


$$
\begin{aligned}
& \rho c \frac{4}{3} \pi\left(\frac{\nabla r}{2}\right)^{3} \frac{t_{0}^{i+1}-t_{0}^{i}}{\nabla r}=4 \pi \lambda\left(\frac{\nabla r}{2}\right)^{2} \frac{t_{1}^{i}-t_{0}^{i}}{\nabla r} \\
& \begin{array}{l}
\Rightarrow O=\frac{a \nabla \tau}{\nabla r^{2}} \leq \frac{1}{6} \\
\rho c \frac{4}{3} \pi\left\{\left[\left(m+\frac{1}{2}\right) \nabla r\right]^{3}-\left[\left(m-\frac{1}{2}\right) \nabla r\right]^{3}\right\} \frac{t_{m}^{i+1}-t_{m}^{i}}{\nabla \tau} \\
=4 \pi \lambda\left[\left(m-\frac{1}{2}\right) \nabla r\right]^{2} \frac{t_{m-1}^{i+1}-t_{m}^{i}}{\nabla r}+4 \pi \lambda\left[\left(m+\frac{1}{2}\right) \nabla r\right]^{2} \frac{t_{m+1}^{i}-t_{m}^{i}}{\nabla r} \\
\text { Mnodes: } 1-\frac{8 m^{2}+2}{4 m^{2}+\frac{1}{3}} F_{0} \geq 0 \\
\text { Convergence condition: } \quad \rho c \frac{4}{3} \pi\left\{(m \nabla r)^{3}-\left[\left(m-\frac{1}{2}\right) \nabla r\right]^{3}\right\} \frac{t_{m}^{i+1}-t_{m}^{i}}{\nabla \tau} \\
=4 \pi \lambda\left[\left(m-\frac{1}{2}\right) \nabla r\right]^{2} \frac{t_{m-1}^{i+1}-t_{m}^{i}}{\nabla r}+h 4 \pi \lambda m^{2} \nabla r^{2}\left(t_{\infty}-t_{m}^{i}\right)
\end{array} \\
& \text { Eleven nodes: }
\end{aligned}
$$

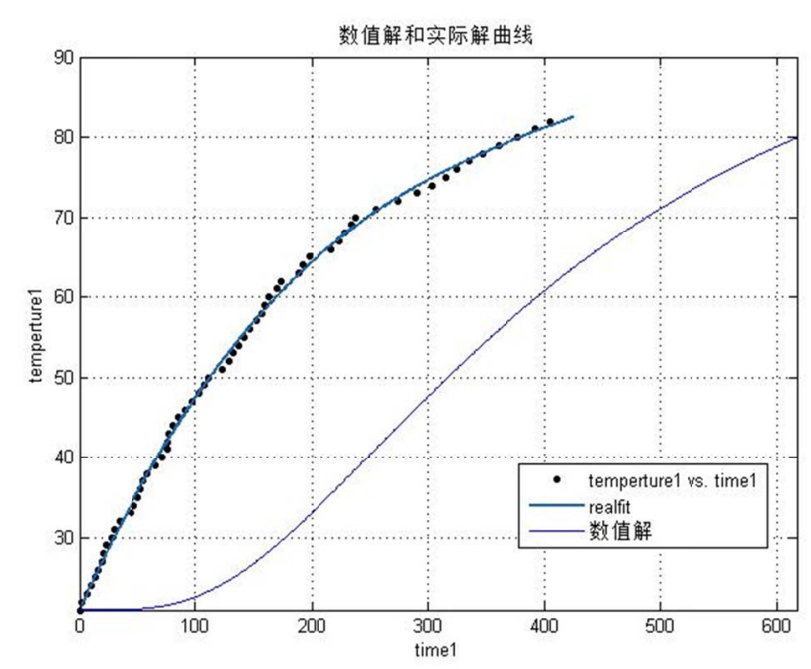

Fig. 4 the regional discrete inside the egg

Because the region is divided into 11 nodes, it gets the $\mathrm{Fo}=0.053$ which meets the convergence criteria, therefore, the iteration result can be obtained by writing MATLAB program as shown in Table 2.

Table 2 rror between the images of numerical method and the real one

\begin{tabular}{|l|l|l|l|l|l|l|l|l|l|l|l|}
\hline Node & 1 & 2 & 3 & 4 & 5 & 6 & 7 & 8 & 9 & 10 & 11 \\
\hline Temperature $^{\circ} \mathrm{C}$ & 99.5276 & 97.3078 & 94.8187 & 92.1754 & 89.5078 & 86.9522 & 84.6427 & 82.7023 & 81.236 & 80.3232 & 80.0144 \\
\hline
\end{tabular}

Plotting the curves:

From the results, there is still great error between the images of numerical method and the real one. And at the beginning, there is a temperature change delay in the numerical image. Through the analysis of heat conduction model, it concludes that because it is assumed that the coefficient of convective heat transfer of boiling water is a constant, while the actual convective heat transfer coefficient may be a change in value, and the egg is assumed as a pure thermal conductivity model but actually it exists two states: convection heat transfer of egg white and conduction after solidification of eggs. 


\section{Conclusion}

Substances in eggs is complex, thermal conductivity, surface emissivity, inaccuracy can cause errors. Analysis error comes from the whole egg assumption and thermocouple movement within the egg.

\section{References}

[1] ZHAO Shu, ZHU Huiren, GUO Tao, et al. Numerical Predictions of Flow and Heat Transfer for Rotating Internal Cooling Channels with Rib Turbulators [J].Journal of Xi'an Jiaotong University. 2014,48(2);

[2] CHEN Jingling, ZHU Xiuhong, WANG Qian, et al. Study on the Heat Convection between Tomato Fruitage and Air [J]. Acta Agriculturae boreali-Sinica. 2012,27(6). 